\title{
Implementation of an Adaptive Learning System that Include Correction of Learning Path Based on the Differentiated Pedagogy and the Bayesian Network
}

\author{
http://dx.doi.org/10.3991/ijes.v3i2.4389 \\ Yassine Zaoui Seghroucheni ${ }^{1}$, Mohammed Al Achhab ${ }^{2}$ and Badr Eddine El Mohajir ${ }^{1}$ \\ ${ }^{1}$ The Faculty of Sciences, Tetouan, Morocco \\ ${ }^{2}$ The National School of Applied Sciences, Tetouan
}

\begin{abstract}
Unified Modeling Language in order to design and implement an adaptive learning system that assigns learning objects according to the Fielder and Silverman learning styles (FSLSM), using the Bayesian networks. This system include also correcting the resultant learning path in the case of a failure in an evaluation, by calculating the similarities in behaviors between the struggling learner and the other succeeding learners, and then correct the corresponding learning path, either by recommending other versions of the same Learning object, which are designed previously according to the recommendations of the differentiated pedagogy, or by going back to his initial profile and correct the outcome of FSLSM according to what is observed as an adopted behavior within the system.
\end{abstract}

Index Terms-Learning Object, Learning Path, implementation, UML, Bayesian Network, Differentiated pedagogy.

\section{INTRODUCTION}

The adaptive learning systems are an important class of the e-learning systems, the significance position they gained in the field, is due primarily to the endless possibilities they offer in terms of personalizing learning path, according to the needs, prerequisites and more importantly the learning styles, which translate obviously to a more satisfactory results on the learner side. Most of the adaptive learning systems build a learner model based on the learner's characteristics. An adaptive learning system is able to provide specific learning object according to the model built previously which create at the end a specific learning path. Somehow the generated learning paths may not be the leading ones. This translates, assessment wise, with a negative result in the evaluation. This represents actually a frequent problem faced in the adaptive learning system, as they appeared to be not flexible enough to offer any correction of those learning path, which may be due to a bad choice of the learning object or even sometimes by not answering correctly the initial test of FSLSM as it was proven that people tend to answer those psychological tests according to what is socially correct.

Through this paper, and by using the UML (Unified Modeling Language), we will design and implement a system that generates learning objects according to the FSLSM [1] based on the Bayesian network, and the rec- ommendations of the differentiated pedagogy [2] which advocate offering multiple versions of the same learning object [3], on which we will rely on to correct the nonleading paths.

This paper is organized as follows:

In section 2 we present the general architecture of the system, then in section 3 we will be discussing the Felder and Silverman Learning styles Model (FSLSM), later we'll put the focus on the importance of the differentiated pedagogy in the learning process, and we will present also the Bayesian network that generate Learning Objects according to the FSLSM. We will accomplish the paper in section 7 with the implementation of the system using the Unified Modeling Language (UML) and presenting the corresponding use case diagram and the class diagram. Finally some conclusions are drawn in section 8 .

\section{THE ARCHITECTURE OF THE ADAPTIVE LEARNING SYSTEM}

In general, an adaptive learning system is composed of Domain model, Learner model and the adaptive model. The adaptation model developed through this paper takes into account the following parameters developed by the authors of [4]:

Learner model: The learner model used is based on the Felder-Silverman learning styles, and the prerequisis of each learner,

Domain Model: The domain model is composed of the learning objects which are designed according to the SCORM Standards, a multiple versions of the same learning object and finally the Content metadata as defined by IEEE Learning object Metadata.

Instruction Model: The instruction model is the pedagogical model responsible for designing the learning object included in the domain object.

Adaptability model: The adaptation model is the one generating learning objects according to the characteristics of learners (prerequisis, learning styles) and the learning objects that match them.

Evaluation: The evaluation is the critical part in this adaptive learning system as it remains the only way to correct learning paths if it appears that the generated learning path is not the leading one. 


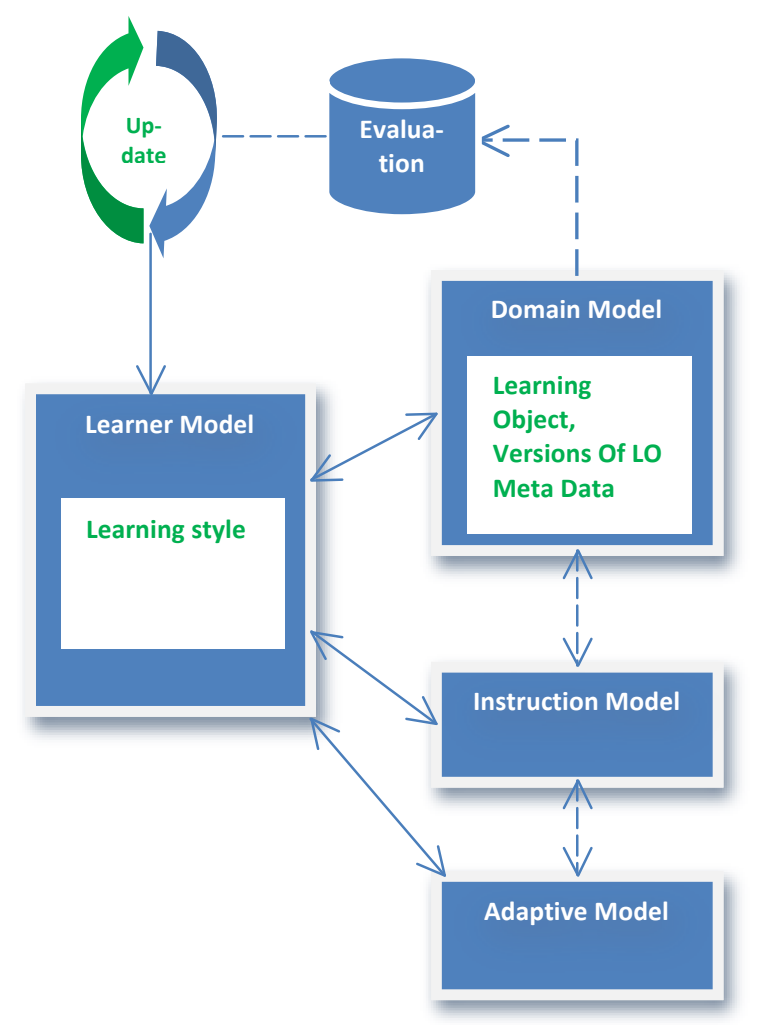

Figure 1. The Adaptive Learning System Architecture

\section{The FELder Silverman LeARning StYle MODEL}

There are many models about learning styles in literature such as Kolb [5], Dunn \& Dunn [6], Honey \& Mumford [7], and Myers-Briggs [8]. This model is based on Felder and Silverman's Learning Styles Model, because of its applicability to e-learning and compatibility to the principles of interactive learning systems design [9].

Students learn in many way by seeing and hearing; reflecting and acting; reasoning logically and intuitively; memorizing and visualizing and drawing analogies and building mathematical models; steadily and in fits and starts [10]. The ways in which an individual characteristically acquires, retains, and retrieves information are collectively termed the individual's learning style [11]. In 1988 R. Felder and L.Silverman proposed a learning style model that classifies five dimensions of learning styles. Lately, inductive/deductive was excluded from the model, so now we deal only with four dimensions (Figure 2).

\section{A. The Index of Learning Styles (ILS)}

Developed by Felder and Soloman, is a questionnaire of 44 items to identify learning styles according FSLSM. As mentioned earlier, each student has a personal preference for each dimension. These preferences are expressed with values ranging from +11 to -11 per dimension, with steps $+/-2$. This range has eleven questions that are asked for each dimension. In response to a question, for example, with an active preference, one is added to the value of the active / Reflective dimension while a response to a preference Reflective decreases the value of 1 . Therefore, each question is answered either with a value of 1 (answer a) or -1 (answer b). Answer a is a preference for the first pole of each dimension (active, sensing, visual, or sequential),

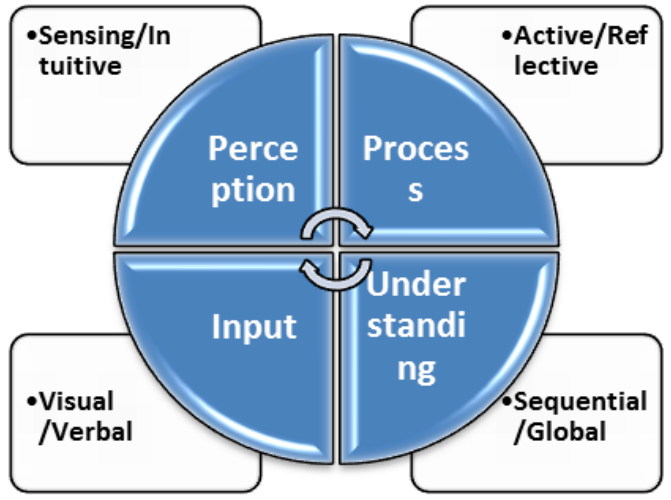

Figure 2. Dimensions of Felder and Silverman Learning Style Model

answer $\mathrm{b}$ is to the second pole of each dimension (Reflective, Intuitive, verbal or Global). The ILS is an index often used and well-studied to identify learning styles. Each learning style dimension seems to include different characteristics. In an empirical study [10], the groups of preferences within each dimension of FSLSM were analyzed and their relevance for each dimension was investigated. Table 1 shows the proposed groups as well as the related answers of ILS questions [23] for each group. A question may appear twice in the table, if the two possible answers to the question point to two different groups.

\section{B. The Learning Styles Combinations}

A learning style combination (LSC) is a 4-tuple composed by one learning Style from each FSLSM dimension: $\mathrm{LSC}=\{(\mathrm{a}, \mathrm{b}, \mathrm{c}, \mathrm{d}) / \mathrm{a} \in \mathrm{D} 1 ; \mathrm{b} \in \mathrm{D} 2 ; \mathrm{c} \in \mathrm{D} 3 ; \mathrm{d} \in \mathrm{D} 4\}$ Where: $\mathrm{D} 1=\{\operatorname{Active}(\mathrm{A}) ; \operatorname{Reflective}(\mathrm{R})\}$

$\mathrm{D} 2=\{$ Sensitive $(\mathrm{S})$; Intuitive $(\mathrm{I})\}$

D3 $=\{$ Visual $(\mathrm{V}$ i $)$; Verbal $(\mathrm{Ve})\}$

$\mathrm{D} 4=\{$ Sequential $(\mathrm{Seq}) ;$ Global $(\mathrm{G})\}$

Therefore, there are 16 possible learning styles combinations:

$\mathrm{LSCs}=\{(\mathrm{A}, \mathrm{Vi}, \mathrm{S}, \mathrm{Seq}), \quad(\mathrm{A}, \mathrm{Vi}, \mathrm{S}, \mathrm{G}), \quad(\mathrm{R}, \mathrm{Vi}, \mathrm{S}, \mathrm{Seq})$, (R,Vi,S,G), (A,Ve,S,Seq), (A,Ve,S,G),

(R,Ve,S,Seq), (R,Ve,S,G),(A,Vi,I,Seq), (A,Vi,I,G),

(R,Vi,I,Seq), (R,Vi,I,G), (A,Ve,I,Seq),

(A,Ve,I,G), (R,Ve,I,Seq), (R,Ve,I,G)\}.

Usually the values of learning styles are stored in the values $[-11 \ldots+11]$, but since we are using those values in a probabilistic context, those values will be stored in the interval [0...100].

$\mathrm{LS}=\{(\operatorname{PrA} ; \operatorname{PrR}) ;(\operatorname{PrS} ; \operatorname{PrI}) ;(\operatorname{PrV} \mathrm{i} ; \operatorname{PrV}$ e); (PrSeq; $\operatorname{PrG}) / \operatorname{PrA}+\operatorname{PrR}=100 ; \operatorname{PrS}+$

$\operatorname{PrI}=100 ; \operatorname{PrVi}+\operatorname{PrVe}=100 ; \operatorname{PrSeq}+\operatorname{PrG}=100\}$.

\section{The DiffERENTIATEd PEDAGOGY}

To differentiate is to break with a pedagogy that is frontal, the same lessons, the same exercises etc...for all learners. The goal is to put everyone in an optimal learning situation. This organization is to use all the educational resources available so that each learner is constantly or at least very often confronted with the most fruitful teaching situation. 
The following part is based on the works of [3], in fact the authors chose to emphasize the following versions of every learning object presented in the system based on the recommendations of [2].

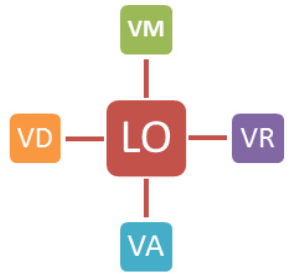

Figure 3. Versions of the same LO

As the chart above shows, there are 4 different versions for the same LO:

a) VM: a multimedia version.

b) VR: a version with a reminder of the previous LO.

c) VD: a version with a deeper level of knowledge.

d) VA: a standard version.

\section{The Bayesian Network Model}

A Bayesian Network (BN) is a graphical model for efficiently representing a joint probability distribution over a set of random variables $\mathrm{V}$. A BN is denoted by $(\mathrm{G}, \mathrm{P})$; where $G$ is a Directed Acyclic Graph (DAG) defined over $\mathrm{V}$ (such graph encodes independence relationships among the variables in $\mathrm{V}$ ); and $\mathrm{P}$ denotes a set of local probability distributions, one for each variable conditioned on its parents. Variables are represented for nodes denoting "concepts" and edges indicating cause/effect dependencies among concepts. Final nodes can be seen as "effects" (values collected from the learning environments), while highest-level nodes can be thought as "causes". Every node can have two or more possible results; each result is named a state of the variable. Thus, once the learner's profile is defined (Learning style according to FelderSilverman and prerequisis) the learner model can be built.

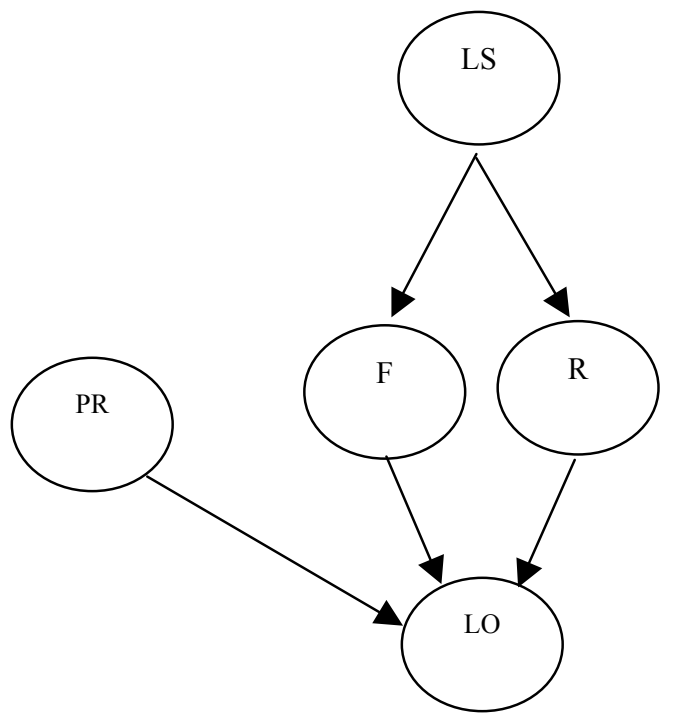

Figure 4. The Bayesian network generating the learning objects
Bayes' law

$\mathrm{P}(\mathrm{F} / \mathrm{LS})=\mathrm{P}(\mathrm{LS} / \mathrm{F}) \mathrm{P}(\mathrm{F}) / \mathrm{P}(\mathrm{LS})$

$\mathrm{P}(\mathrm{R} / \mathrm{LS})=\mathrm{P}(\mathrm{LS} / \mathrm{R}) \mathrm{P}(\mathrm{R}) / \mathrm{P}(\mathrm{LS})$

$\mathrm{P}(\mathrm{LO} / \mathrm{PR}, \mathrm{F}, \mathrm{D})=\mathrm{P}(\mathrm{PR}, \mathrm{F}, \mathrm{D} / \mathrm{LO}) \mathrm{P}(\mathrm{LO}) / \mathrm{P}(\mathrm{PR}, \mathrm{F}$,

D)

Knowing that:

$\mathrm{P}(\mathrm{PR}), \mathrm{P}(\mathrm{LS})$, are representing the A priori probabilities. F: Learning object Format $=\{$ video, text, audio, picture $\}$ R: Learning object Unit $=\{$ exercise, example, outline... $\}$ PR: prerequisis $=\{$ Low, Average, High $\}$

\section{The ImPlementation Of The System}

The implementation and the design of the adaptive learning system is done using the modeling language UML (Unified Modeling Language), this system operates according to the following scenario:

\section{A. The Use Case diagram of the adaptive learning system}

In Figure 5 is the use case diagram of the adaptive learning system designed according to the scenario seen in the last subsection, in fact in this diagram, there are three actors namely: the learner, the teacher and the adaptive system.

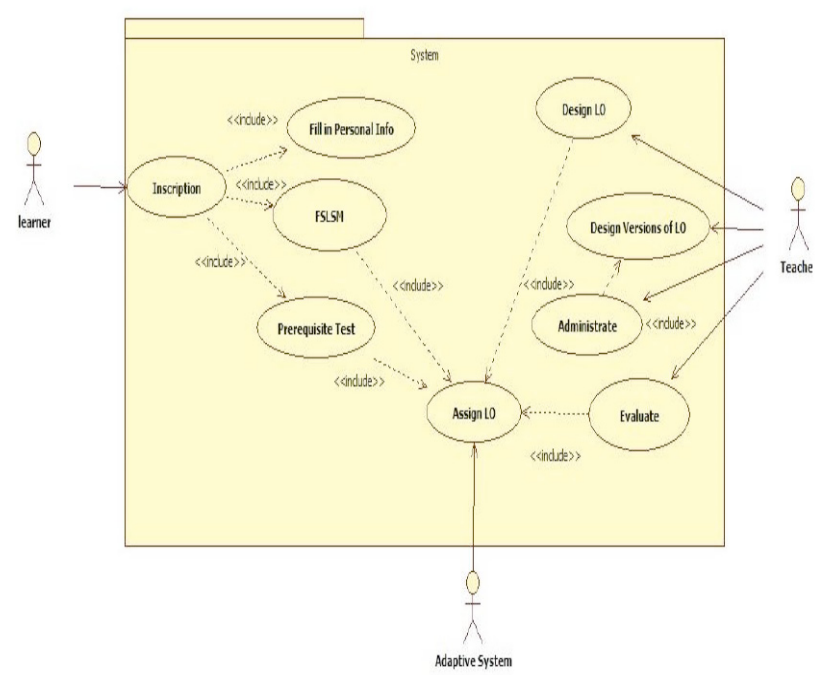

Figure 5. the Use Case diagram

For a first-timer, the learner must fill-in a form containing several personal informations, answering a prerequisites test, and finally answers the Felder-Silverman questionnaire.

The role of the teacher is to design, Learning objects, different versions of the same learning object, evaluate, and finally administrate the system by deleting from the system the less relevant versions.

\section{B. The class Diagram of the adaptive learning system}

Figure 6 represents the class diagram of the adaptive learning system; it contains obviously several methods that will be explained later in table I. 


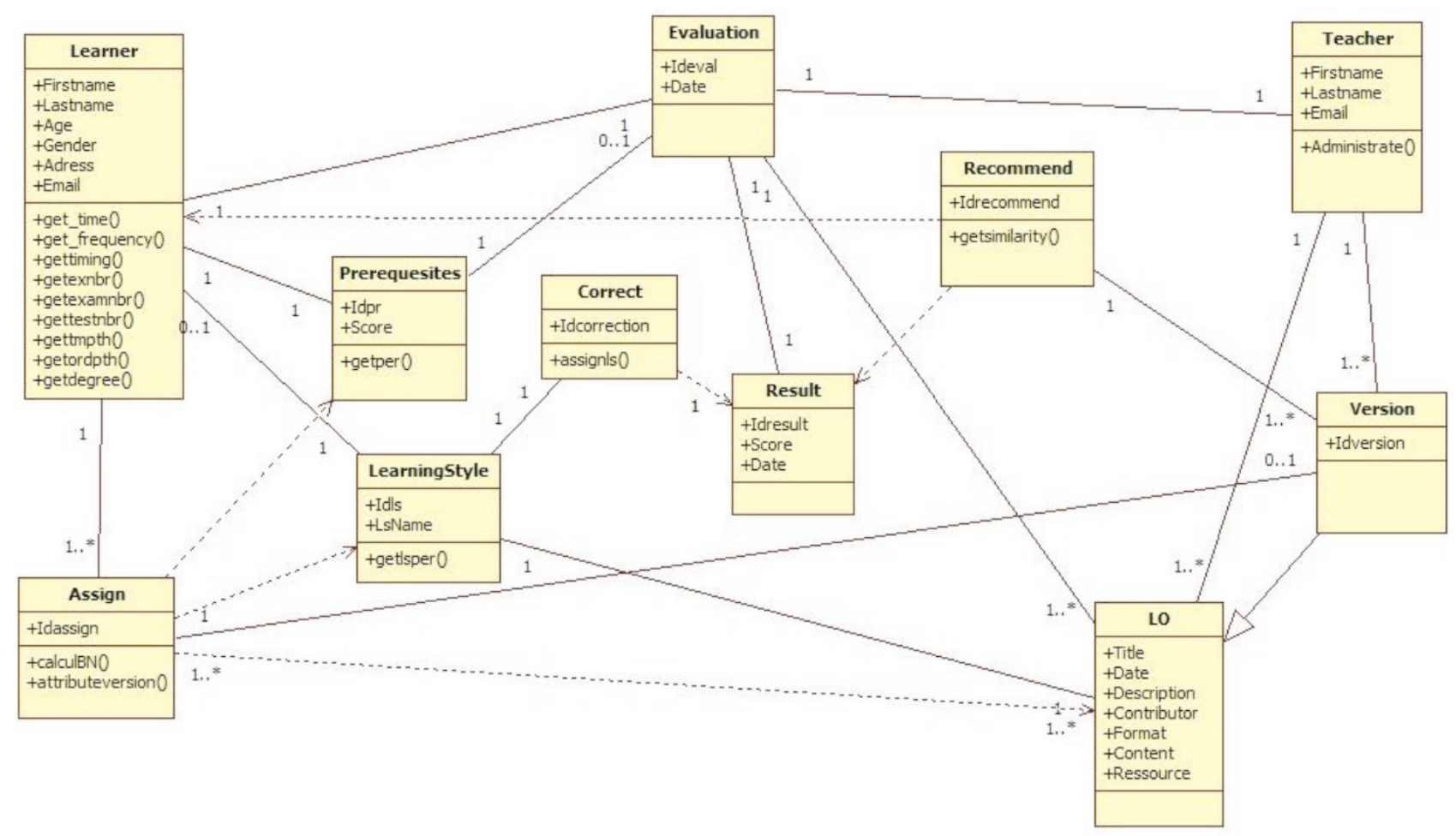

Figure 6. The class diagram of the adaptive learning system

TABLE I

DESCRIPTION OF THE DIFFERENT METHODS APPEARING IN THE ClASS DiAGRAM

\begin{tabular}{cll}
\hline Class & \multicolumn{1}{c}{ Method } & \multicolumn{1}{c}{ Description } \\
\hline Learner & get_time() & To calculate the time spent at each connection \\
& get_frequency() & To calculate the frequency of the connections \\
& gettiming() & To get the timing of connection compared to the evaluation \\
& getexnbr() & To get the number of the viewed exercises \\
& getexamnbr() & To get the number of the viewed examples \\
& gettestnbr() & To get the number of the executed tests \\
& gettmpth() & To get the time allocated to the theoretical part \\
& getordpth() & To get the order in which the learning objects were browsed \\
& getdegree() & To calculate the degree of participation in forums, chat.. \\
LearningStyle & getlsper() & To convert the obtained learning style into a percentage \\
Prerequisites & getper() & To calculate the percentage of the prerequisite test \\
Teacher & Administrate() & Mainly to eliminate from the system the non-relevant versions of the learning object \\
Recommend & get_similarity() & To calculate the similarity between the struggling learner and the succeeding ones \\
Correct & assignls() & To correct the learning style \\
Assign & calculBN() & To calculate according to Bayes law the relevancy of a Learning object based on the \\
& result of LS and the prerequisites test \\
& atributeversion() & To recommend a version to the learner \\
\hline
\end{tabular}

Here is above, the table 1 recapitulating the different methods appearing in the class diagram with their corresponding descriptions.

\section{CONCLUSION}

Through this paper, we presented the use case diagram and the class diagram of an adaptive learning system, that assign learning objects according to the learning styles and prerequisites of each learner, using the calculations of a Bayesian network, and by correcting the non-leading paths either by recommending the most relevant versions to the struggling learner or correcting the initial FSLSM test. The next step is to implement this system, and test it on a sample of learners and discuss the outcome results.

\section{REFERENCES}

[1] Felder, R.M. and L.K. Silverman, Learning Styles and Teaching Styles in Engineering Education, Presented at the 1987 Annual Meeting of the American Institute of Chemical Engineers, New York, Nov. 1987.

[2] Philippe Meiriu, Apprendre... oui, mais comment?, ESF éditeur, Paris, $1987,17^{\circ}$ edition, 1999.

[3] Seghroucheni, Y. Z., Mohammed, A., \& El Mohajir, B. E. (2014). An Approach to Create Multiple Versions of the Same Learning Object. International Journal of Emerging Technologies in Learning (iJET), 9(5), pp-17. http://dx.doi.org/10.3991/ijet.v9i5.3762

[4] Seghroucheni, Y. Z., Mohammed, A., \& El Mohajir, B. E. (2014). A Recommendation System Operating after Assessment to Correct Learning Paths in a Content Adapting System. International Journal of Computer Applications, 93. 
[5] Kolb, A.Y., Kolb, D.A.: The Kolb Learning Style Inventory Version 3.1, Technical Specification. Hay Group, Boston (2005)

[6] Dunn, R., Dunn, K., Price, G.E.: Learning Style Inventory, Lawrence, KS. Price Systems (1996)

[7] Honey, P., Mumford, A.: The Learning Styles Helper‘s Guide. Peter Honey Publications Ltd., Maidenhead (2006)

[8] Myers, I.B., McCaulley, M.H.: Manual: A Guide to the Development and Use of the Myers-Briggs Type Indicator. Consulting Psychologists Press, Palo Alto (1998)

[9] Kuljis, J., Liu, F.: A Comparison of Learning Style Theories on the Suitability for Elearning. In: Hamza, M.H. (ed.) Proceedings of the Iasted Conference on Web Technologies,Applications, and Services, pp. 191-197. ACTA Press (2005)

[10] Felder, R., Silverman, L.: Learning and Teaching Styles. Journal of Engineering Education 94(1), 674-681 (1988)
[11] Felder, R., Henriques, E.R.: Learning and Teaching Styles In Foreign and Second Language Education. Foreign Language Annals 28(1), 21-31 (1995) http://dx.doi.org/10.1111/j.19449720.1995.tb00767.x

\section{AUTHORS}

Y. Z. Seghroucheni is with the Faculty of Sciences of Tetouan (e-mail: yassinezaouiseghroucheni@gmail.com).

M. AL Achhab, is with the National School of Applied Sciences of Tetouan (e-mail: alachhab@gmail.com).

B. E. El mohajir is the Faculty of Sciences of Tetouan (e-mail: b.elmohajir@ieee.ma)

Submitted 18 January 2015. Published as resubmitted by the authors 12 May 2015. 